\title{
How Collaborative Culture Supports for Competitive Advantage: The Mediating Role of Organizational Learning
}

\author{
Hui Lei ${ }^{1}$, Phong Ba Le ${ }^{1,2} \&$ Hanh Thi Hong Nguyen ${ }^{1}$ \\ ${ }^{1}$ School of Business Administration, Hunan University, Changsha, Hunan, China \\ ${ }^{2}$ Hanoi University of Industry, Tuliem, Hanoi, Vietnam \\ Correspondence: Hanh Thi Hong Nguyen, Hunan University, Business School, Yuelu Mountain, Changsha, Hunan, \\ China.
}

Received: February 24, 2017

Accepted:March 9, 2017

Online Published: March 14, 2017

doi:10.5430/ijba.v8n 2p73

URL: https://doi.org/10.5430/ijba.v8n2p73

\begin{abstract}
The paper aims to clarify the influences of collaborative culture and specific aspects of organizational learning on competitive advantage. Structural equations modeling (SEM) is applied to test degree of influence of each variable has on each other through using data collected from 298 participants at 150 large manufacturing and service firms. The result shows that organizational learning act as mediating roles in the relationship between collaborative culture and competitive advantage. Our results indicate that collaborative culture practices will yield significant effects to competitive advantage directly or indirectly through improving specifics aspects of organizational learning. The findings of this study provide a theoretical basis, which can be used to analyze relationships between collaborative culture, specifics aspects of organizational learning and competitive advantage. From a practical perspective, the study brings more deeply understanding for CEOs/managers about the necessary factors to encourage and promote firm's competitive advantage.
\end{abstract}

Keywords: organizational culture, collaborative culture, organizational learning, differentiation competitive advantage, cost competitive advantage, SEM

\section{Introduction}

Resource-based view points out that, if resources and capabilities of the firms converging four important characteristics: values, scarce, difficult to imitate and non-replaceable, competitive advantage will be shaped and enables firms having high operating efficiency and getting profits above the average (Barney, 1991; Wu, 2010). However, competitive advantages, which the firms achieved base on its advantages of resources and capabilities can be only effective in the short term and may be ineffective in the long term due to fast changing and difficult to predict of competitive environment, making advantages of firm's resources and capabilities no longer be maintained continuously (Helfat \& Peteraf, 2003). To maintain a competitive advantage in the long term, many researches mentioned the construction of organizational learning model as the vital solution. Organizational learning (OL) is the source for the achievement of sustainable competitive advantage (Brockman \& Morgan, 2003; Gould, 2009). As a corollary, OL is often faster and more flexible in responding to the challenges in relation to competitors, allowing firms to maintain competitive advantage in the long term (Slater \& Narver, 1995).

Realizing the very important role of OL, scholars continue increasing understanding of paths to organizational learning. Farrukh and Waheed (2015) integrated the viewpoints of different researchers about OL and concluded some critical factors, including: facilitative leadership; self-development, empowerment; and information sharing and culture of collective collaboration. These factors could be present in the organization to become an OL. In particular, Lopez, Peon \& Ordas (2004) suggested that collaborative culture (CC) has positive effects on OL. The authors stated that, the basic values of culture (including: long-term view and anticipate changes; communication and dialogue; respect and empowerment; team-work; risk assumption, ambiguity tolerance and encourage for diversity) can be called as CC, which will encourage OL.

Every organization have its own culture, while the $\mathrm{CC}$ is core values of culture, which are always constant and very important for establishing norms and standards within organizations, that influences all aspects of organization life both organizational effectiveness and individual satisfaction (Miron, Erez \& Naveh, 2004). However, little empirical 
research has been conducted investigating the specific links between: CC and specific parts of OL (including: information acquisition, knowledge dissemination, shared interpretation, and organizational memory); OL and two kinds of competitive advantage (differentiation and low cost); as well as the relationship among these factors from a holis tic perspective. So, it limited our understanding of the different ways firms can use to get competitive adv antage. In that context, this study is done aim to explore the specific and effective way to promote firms' competitive advantage. Research results are expected to have significant contributions in CC practice to stimulate OL, thereby promoting competitive advantage for firms. Our study attempts to address the following research questions:

- Whether CC has positive impacts on OL or not?

- Whether CC influences competitive advantage directly or not?

- Do specific aspects of OL have mediating role in relationships between CC and competitive advantage?

- How different are CC's influences on specific parts of OL and competitive advantage?

To answer these questions, structural equations modeling (SEM) is applied to investigate degree of influence of each variable has on each other based on a survey of 298 participants from 150 large manufacturing and service firms in Vietnam. The first goal of this study is analysis and provision empirical evidences for the relationship between CC, specific aspects of OL and two kinds of competitive advantage in a model. Second goal, this study does not just estimate the direct influences of $\mathrm{CC}$ on competitive advantage, but also explore more specifically the impact mechanis ms by analyzing the mediating role of OL. Third goal, by discussing more deeply about the influences of $\mathrm{CC}$ on specific aspects of OL, which in turn lead to competitive advantage, this study offers specific solutions for CEOs/managers performing successfully direction of selected strategy which is differentiation or low cost by focusing right neces sary efforts in right activity.

The remainder of th is study is arranged as follows. Part 2 presents the literature review for the concepts in proposed model and develops a research model to portray hypothesized relationship. Part 3 provides research methods to test the model and data collection. Part 4 analyzes the data and discusses the empirical result. Finally, this study gives some conclusions, managerial implications, its limitations and makes proposals for future research in Part 5.

\section{Literature Review and Hypotheses Development}

\subsection{Collaborative Culture and Organizational Learning}

Organizational learning (OL) is a hot topic, and it has a huge attraction in social scientific research. At the same time, the literature on OL increasingly rich and development (Slater \& Narver, 1995; Brockmand \& Morgan, 2003; Jiménez-Jiménez \& Sanz-Valle, 2011; Santos-Vijande, López-Sánchez \& Trespalacios, 2012). There are some different interpretations of the OL. Lewis (2002) show that, OL is an organization that constantly creates, disseminates and integrates new knowledge and incessantly modifies its action based on new knowledge and awareness. OL helps firms to develop mechanisms and processes encouraging both individual and group workplace learning (Armstrong \& Foley, 2003). In this study, we use the concept that OL is a process including four basic activities: information acquisition (IA), knowledge dis semination (KD), shared interpretation (SI) and organizational memory (OM) (Slater \& Narver, 1995; Weerd, Pacitti, Silva Gomes \& Pearson, 2002). In which IA is the process that company collects new information and knowledge from internal sources and environmental external sources; $\mathrm{KD}$ is the process of sharing knowledge to every individual and division in the entire organization; SI is the process of explaining significance of the information as well as significance of information for the organization to aim achieving unity in perception towards the disseminated information; OM is the process of s toring information and knowledge that has been gathered and ready to meet the demand for information and knowledge when every individuals and divisions in entire organization have need in the future. In this way, staff rotation and staffing fluctuations will not lose information (Cross \& Baird, 2000) as well as have no bad affects to firm operation.

For collaborative culture, Ruth (2001) proposed that collaboration implies mutual interdependence as well as mutual respect. Each of the participants must bring something of value to the collaborative table. Successful collaboration is based on a shared vision, common goals, and a climate of trust and mutual respect (Muronaga \& Harada, 1999). CC encourages total involvement of team members because in a collaborative culture, team members have mutual respect, care and support of each other (Bstieler \& Hemmert, 2010). In this study, we use the concept of Lopez et al., (2004), they define CC as the basic values of culture with following specific values: A long-term vision and advance management of the change, team-work, communication, risk assumption, respect and empowerment, and promoting the knowledge of individuals. 
Empirical researches on relationship between CC and OL are still sparse and limited. Ho wever, this topic attracted the attention of some authors. Lopez et al., 2004 appointed that, $\mathrm{CC}$ helps members in organization to have a common objective and work together effectively by sharing knowledge and learning from one another. These shared values constitute the foundation of communication and mutual understanding. As the basic values of culture, CC has positive effects on OL by many reasons. It allows the activities involving individuals collecting data from various sources, using their evaluation to change data into information and then engaging in high interaction and discuss to create new knowledge. To attain a good working environment, developing ability to learn, many organizations try to implement a culture which not only promote communication between their member, experimentation and risk taking but also encourage employee to question fundament beliefs and work pattern (Lopez et al., 2004). Values of culture has influences on knowledge sharing behaviors by shaping patterns and qualities of interaction needed to enhance knowledge and information among individuals (David \& Fahey, 2000; Alavi, Kayworth \& Leidner, 2005). CC encourage members in embracing change, offering different viewpoints and discussing problems openly for leading to constructive collaboration and consensus (Lopez et al., 2004). It provides norms and rules for behavior in organizations, thereby effect on how people communicate and share knowledge by forming an organizational context for social interplay and creates norms concerning what is 'right' and 'wrong' (David \& Fahey, 2000; Ajmal \& Koskinen, 2008).

Some management practices can promote learning relationship, such as cultivating a CC and development of relations of trust (Selnes \& Sallis, 2003). Sveiby and Simons (2002) actually underline that, in an organizational culture context, fulfilling the collaboration among three levels of the organizational hierarchy: the business unit, the direct superiors and coworkers in a workgroup, enables the organization to maximize knowled ge sharing.

In general, the above arguments support for the CC's positive influences on OL. However, empirical researches on relationship among these factors are still sparse and limited; to my knowledge, only the study of Lopez et al. (2004) mentioned the positive relationship between CC and OL. Aim to explore more deeply relationship between CC and four specific parts of OL we propose following hypotheses (see Fig ure 1):

H1a.b.c.d: CC has positive influences on IA, KD, SI, and OM, respectively.

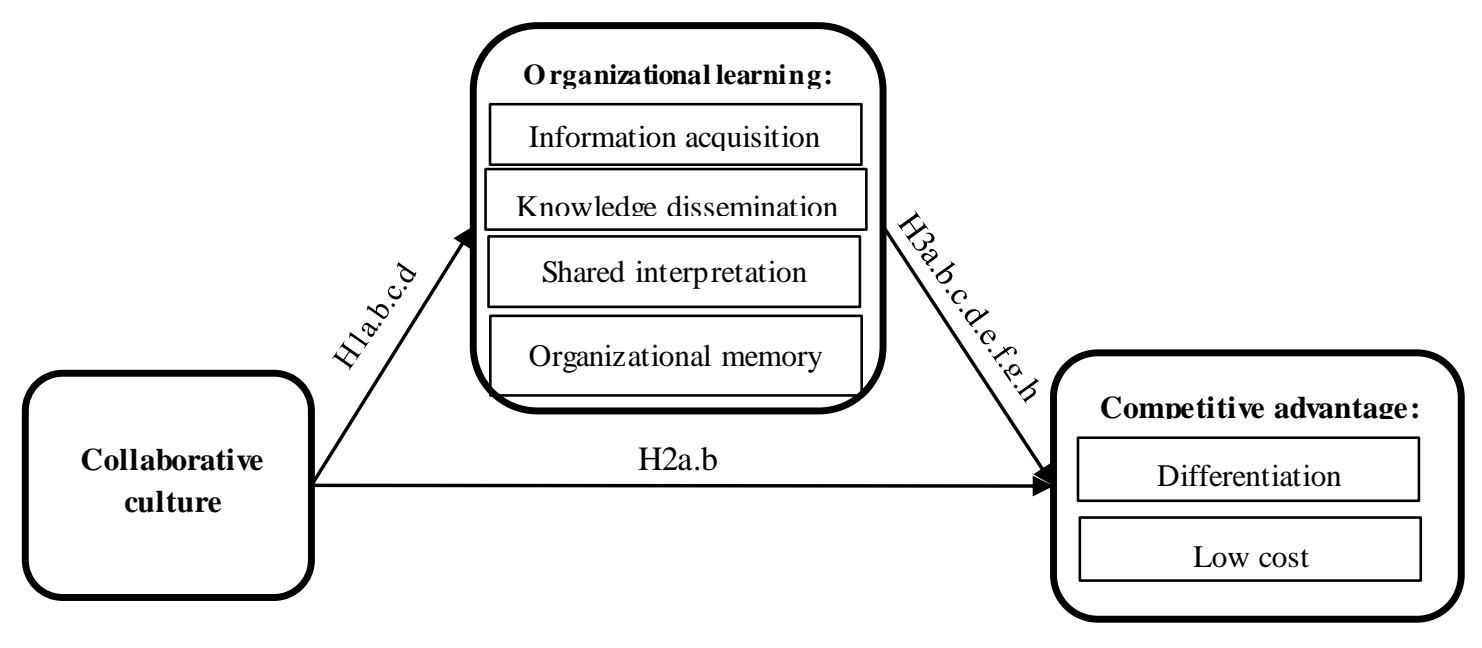

Figure 1. Conceptual model

\subsection{Collaborative Culture and Competitive Advantage}

Resource-based view showed that: if a firm's resources and capabilities are values, scarce, inimitable, and non-replaceable (VRIN), the firms may create competitive advantage by having high operating efficiency and getting profits above the average (Barney, 1991; Wu, 2010). Besides, an organization is said to achieve a competitive advantage if it occupied some positions by implementing a value creating strategy and gaining sustainable benefits from the strategy, simultaneously competitors are unable to copy its successful strategy (Porter, 1985; Coyne, 1986; Barney, 1991). According to Porter's (1980) typology of competitive strategy, firms should rely on their own resources shaping the activities to create cost advantage or differentiation advantage. Although Porter (1980) initially did not believe implementing two strategies at the same time, the author later acknowledged that many firms have 
found ways to reduce costs without damaging the level of difference, even really make their differentiation increases (Porter, 1985). Besides, previous studies also focused on actual availability to simultaneously achieve two advantages: cost and differentiation (Hamel \& Prahalad, 1989; Day, 1990). Therefore it implicitly ad mitted that, two strategies can coexist and represent a level of perfect competition (Vorhies, 1998).

Many previous studies refer to the positive relationship between collaborative culture and organizational performance as well as competitive advantage. Kotter and Heskett (1992) find that, values of culture has been employed as independent and suitable competition factor, especially at hyper-dynamic markets as in the case of Hewlett-Packard, Nissan, Zappos. It is also a crucial factor to organizational effectiveness (Denison, 1990; Gordon \& Di Tomaso, 1992). Barney (1991) noted that because resources are diversely distributed among firms, so only a firm's unique resources may lead to persistently superior performance and achieving competitive advantage. Moreover, from resource-based view, we found that $\mathrm{CC}$ can be a kind of core competence and provide firms competitive advantage by some main characteristic: va luable, rare, inimitable, and difficu lt to replace. CC is valuable because it is an effective platform for progress within the organization (Carter, 1999; Weiss, 1999). More specially, $\mathrm{CC}$ is a valuable competence in creating better communication, stimulating information sharing and making greater co-operation (Calton \& Lad, 1995; Whitener, Brodt, Korsgaard \& Werner, 1998), as an apparent result it leads to greater creative efforts. CC is also very difficult for competitor to imitate and transfer because one of the most important characteristic of culture is tacit, intangible and high complexity (Coyne, 1986). Simultaneously, to reduce organizational conflict and work effectively across borders, firms try to assess and merge diverse skills that exist in different functions and across different organizations (Sanders, 2007; Wang \& Wei, 2007). W ith these realities, scholars suggest that collaboration can act as a valued dynamic capability (Agarwal \& Selen, 2009) and it makes CC becoming a special resource and very difficult to replace. Similarly, CC is also rare because it is very difficult for firms to have a successful CC. So, many authors try to study and offer principles for effective collaboration (e.g., Jones 2000; Ruth, 2001).

Aim to explore more deeply relationship between CC and two specific kinds of competitive advantage we propose following hypotheses (see Fig.1):

H2a.b: CC has positive impacts on differentiation and low cost competitive advantage.

\subsection{Organizational Learning and Competitive Advantage}

A number of scholars introduce the concept of OL as a norm for achieving organizational profitability and obtaining sustainable (e.g., Thomas \& Allen, 2006; Dav is \& Daley, 2008). OL has a positive impact to the firm's competitive advantage. It also has significant and positive impacts on the human resource performance and firms operating performance (Azadegan \& Dooley, 2010; Bell, Mengüç \& Widing II, 2010).

Santos-Vijande et al. (2005) emphasized that OL has expanded ability to develop successful strategies aim establishing and maintaining profitable customer relationships. So, if a firm performs on the paradigm of OL, it will has ability to cope well with emerging market opportunities and threats, and enable firms to use effectively its resources to meet market trends and demands (Chauhan \& Bontis, 2004; Yeung, Lai \&Yee, 2007). It helps firms creating favorable conditions for interaction between staff and customers, as well as supplies expanded and useful information about customer needs, tastes and selection criteria (Chenhall, 2005) and thus increasing satisfaction and loyalty of the customer as well as reinforces organization's brand name and image (Zhao, Li, Lee \& Chen, 2011). Further, many previous studies evaluate OL as the source for the achievement of sustainable competitive advantage (Garvin, 1993; Brockman \& Morgan, 2003; Gould, 2009). OL has a positive effect on a firm's competitive strategy and performance (Santos-Vijande et al. 2012)

Although many previous studies mention the positive relations hip between OL and competitive advantage but few researchers consider the specific OL's influences on differentiation competitive advantage (DA) and low cost competitive advantage (CA). So this study proposes following hypotheses (see Fig.1):

H3a.b: IA has positive impacts on DA and CA, respectively.

H3c.d: KD has positive impacts on DA and CA, respectively.

H3e.f: SI has positive impacts on DA and CA, respectively.

H3g.h: OM has positive impacts on DA and CA, respectively. 


\section{Research Methodology}

\subsection{Sample and Data Collection}

In summer 2015, empirical data were collected through a survey of 150 large manufacturing and service firms in three most development provinces of Vietnam (Hanoi, Haiphong, and Hochiminh). We communicate with representatives of these firms by phone and/or make personal visits to explain the purpose of the research and ask for their assistance in collecting the questionnaires. In order to meet research needs, the respondents in this study are CEOs/directors/managers to ensure a necessary understand of the firm as well as firm's strategy. The measurement items are adapted fromexiting scales in the literature for developing an initial list of items. We carry out pilot tested by mean of in-depth interviews with five outstanding academic scholars who have deep knowledge in knowledge manage ment at three university and 45 participants from five firms to determine the efficiency of the questionnaire before the process of formal data collection. This study issues 600 questionnaires and receives 335 copies in the formal data collection, among which 298 ones are valid, with a $49.6 \%$ valid rate. This response rate is similar to those obtained by others who have surveyed top management (e.g., Wang \& Wang, 2012) and to those have studies similar issues in strategic management (e.g., Decarolis \& Deeds, 1999).

Potential non-response bias was assessed by following the method proposed by Armstrong and Overton (1977). Chi-square and independent sample T-test were used to compare the earlier 80 respondents and the last 80 ones based on demographic variables, including gender, age, and level of education. The results demonstrated that there were no significant differences between the two groups of responses ( $>0.05)$. Therefore, it showed that common method bias was not a concern.

\subsection{Variable Measurement}

To ensure the validity and reliability of the study, items used to measure variables that have been previously developed and used from previous studies. All constructs were measured using multiple items and all items are measured via five-point Likert-type scales, ranging from "1" (strongly disagree) to "5" (strongly agree).

\subsubsection{Collaborative Culture}

We used eight items developed by López et al. (2004) to assess firm's collaborative culture: vision and prediction about changes in the long term, encouragement of dialogue between members in the firm, trust and respect the personal views, teamwork, empo werment, a mbiguity tolerance, risk assumption and encouragement for diversity. A sample item is "collaboration and co-operation among the different duties and departments are encouraged".

\subsubsection{Organizational Learning}

In order to access this variable, this study considers organizational learning as the process, which includes four processes: acquisition of information, dissemination of knowledge, shared interpretation and organizational memory (Slater \& Naver, 1995). According to that, organizational learning was measured using an existing scale developed by Sánchez et al. (2011). Some sample items are: "the employees are informed of how the firm was created and its philosophy of work"; "we have a meeting schedule among departments to integrate the existing information"; "we systematically examine and update our opinion about the business environment"; and "person nel turnover does not risk our capacity to create new knowledge and solve problems."

\subsubsection{Competitive Advantage}

Competitive advantage was measured by seven items to express two kind of competitive advantage: differentiation (4 items scale), a sample item is "creation of a brand image identifying the firm"; and costs advantage ( 3 items scale), a sample item is "efforts are made to reach economies of scale". These items derived from the research of Molina-Azorín, Tarí, Pereira-Moliner, López-Gamero and Pertusa-Ortega (2015).

\subsection{Data Analysis Methods}

Analysis of Moment Structures (AMOS) was employed for measurement validation and for testing the structural model based on the data gathered from the 298 respondents in 150 large manufacturing and service firms. Data analysis was conducted by using SPSS and AMOS version 21. Confirmatory factor analysis (CFA) was imple mented to examine the validity and reliability of the constructs.

\section{Data Analysis and Results}

\subsection{Measurement Model}

We firstly tested the reliability of the measures for the constructs by examining the individual Cronbach's alpha coefficients, with result's statistic ranges from 0.81 to 0.93 , which were all higher than the recommended level of 0.7 
(Nunnally \& Bernstein 1994). We then performed confirmatory factor analysis (CFA) evaluating overall measurement model to assess in term of the convergent and discriminant validity.

In order to evaluate the convergent validity as the recommendation of Hair, Black, Babin, Anderson, \& Tatham, (2006), we adopted three primary measures: (1) the factor loadings of the indicators must be statistically significant with values greater than 0.6 ; (2) the values of composite reliability (CR) need greater than 0.7 ; and (3) values of average variance extracted (A VE) need greater than 0.5. As shown in Table 1, all factor loadings range from 0.60 to 0.98 (all larger than 0.6) with statistically significant at the 0.001 level; CR values (ranging from 0.83 to 0.92 ) are higher than 0.7; and the AVE values range from 0.51 to 0.75 (all greater than 0.5). Overall, all the measures exhibited adequate convergent validity. Table 1 shows the means, standard deviation (SD), factor loading, A VE, CR and $\mathrm{C} \alpha$ of every constructs.

Table 1. Result of CFA and internal reliable testing

\begin{tabular}{|c|c|c|c|c|c|c|c|c|}
\hline Construct & Mean & SD & Item & Loading & $\mathrm{AVE}$ & $\begin{array}{l}\text { The square } \\
\text { root of AVE }\end{array}$ & $\mathrm{CR}$ & $\mathrm{C} \alpha$ \\
\hline \multirow[t]{6}{*}{ Collaborative culture } & 3.56 & 0.45 & $\mathrm{CC} 1$ & 0.70 & 0.63 & 0.79 & 0.91 & 0.91 \\
\hline & & & $\mathrm{CC} 2$ & 0.68 & & & & \\
\hline & & & $\mathrm{CC} 4$ & 0.65 & & & & \\
\hline & & & $\mathrm{CC} 5$ & 0.97 & & & & \\
\hline & & & CC6 & 0.94 & & & & \\
\hline & & & $\mathrm{CC} 7$ & 0.73 & & & & \\
\hline \multirow[t]{7}{*}{ Information acquisition } & 3.53 & 0.49 & IA 1 & 0.73 & 0.60 & 0.77 & 0.92 & 0.93 \\
\hline & & & IA 2 & 0.98 & & & & \\
\hline & & & IA4 & 0.60 & & & & \\
\hline & & & IA6 & 0.76 & & & & \\
\hline & & & IA8 & 0.97 & & & & \\
\hline & & & IA9 & 0.68 & & & & \\
\hline & & & IA 10 & 0.61 & & & & \\
\hline \multirow[t]{5}{*}{ Knowledge dissemination } & 3.60 & 0.43 & KD1 & 0.80 & 0.51 & 0.71 & 0.83 & 0.81 \\
\hline & & & KD2 & 0.60 & & & & \\
\hline & & & KD4 & 0.74 & & & & \\
\hline & & & KD5 & 0.65 & & & & \\
\hline & & & KD6 & 0.77 & & & & \\
\hline \multirow[t]{4}{*}{ Shared interpretation } & 3.79 & 0.44 & SI1 & 0.85 & 0.69 & 0.83 & 0.89 & 0.84 \\
\hline & & & SI2 & 0.91 & & & & \\
\hline & & & SI5 & 0.61 & & & & \\
\hline & & & SI6 & 0.92 & & & & \\
\hline \multirow[t]{5}{*}{ Organizational memory } & 3.68 & 0.53 & OM2 & 0.87 & 0.65 & 0.81 & 0.90 & 0.89 \\
\hline & & & OM4 & 0.87 & & & & \\
\hline & & & OM5 & 0.73 & & & & \\
\hline & & & OM6 & 0.65 & & & & \\
\hline & & & OM7 & 0.89 & & & & \\
\hline \multirow[t]{4}{*}{ Differentiation CA } & 3.77 & 0.55 & DA1 & 0.80 & 0.75 & 0.87 & 0.92 & 0.92 \\
\hline & & & DA2 & 0.92 & & & & \\
\hline & & & DA3 & 0.92 & & & & \\
\hline & & & DA4 & 0.79 & & & & \\
\hline \multirow[t]{3}{*}{ Costs competitive advantage } & 3.65 & 0.49 & CA1 & 0.83 & 0.71 & 0.84 & 0.88 & 0.87 \\
\hline & & & CA2 & 0.75 & & & & \\
\hline & & & CA3 & 0.91 & & & & \\
\hline
\end{tabular}

Notes: $\mathrm{C} \alpha \geq 0.7$; composite reliability $\geq 0.7$; average variances extracted $\geq 0.5 ; * * *$ Significant at $\mathrm{p}<0.001$. 
Discriminant validity is the degree to which, factors that a Discriminant validity is the degree to which, factors that are supposed to measure a specific construct do not predict conceptually unrelated criteria (Kline 2010). This study used Fornell and Larcker's (1981) measure of average variance extracted to assess the discriminant validity. In this approach, the discriminant validity of the research instrument was assessed by comparing the square root of the AVE with the correlations among the latent variables. Table 2 shows that the square root of A VE for each construct (diagonal elements in bold) is greater than the correlations among constructs in the model. In general, the results provide strong support for the construct reliability, as well as for the convergent and discriminant validity of the scales.

Table 2. Correlations and average variances extracted from constructs

\begin{tabular}{lccccccc}
\hline Construct & CC & IA & KD & SI & OM & DA & CA \\
\hline Collaborative culture (CC) & $\mathbf{0 . 7 9}$ & & & & & & \\
Information acquisition (IA) & 0.32 & $\mathbf{0 . 7 7}$ & & & & & \\
Knowledge dissemination (KD) & 0.35 & 0.49 & $\mathbf{0 . 7 1}$ & & & & \\
Shared interpretation (SI) & 0.33 & 0.45 & 0.34 & $\mathbf{0 . 8 3}$ & & & \\
Organizational memory (OM) & 0.49 & 0.53 & 0.58 & 0.51 & $\mathbf{0 . 8 1}$ & & \\
Differentiation CA (DA) & 0.44 & 0.53 & 0.51 & 0.44 & 0.65 & $\mathbf{0 . 8 6}$ & \\
Costs competitive advantage (CA) & 0.46 & 0.56 & 0.56 & 0.43 & 0.58 & 0.57 & $\mathbf{0 . 8 4}$ \\
\hline
\end{tabular}

Note: Diagonal elements (in bold) are the square root of the AVE and Off-diagonal elements are the correlations among constructs.

In order to measure the degree fit of the model we evaluated following indicators: absolute fit measures including Chi-square/df (CMIN/df), goodness of fit index (GFI) and root mean square error of approximation (RMSEA); incremental fit measures including normed fit index (NFI), adjusted goodness of fit index (AGFI) and comparative fit index (CFI); parsimonious fit measures including parsimony goodness-of-fit index (PGFI) and parsimony normed fit index (PNFI). With results shown in Table 3, all fit indices meet satisfactory levels. Therefore, it demonstrated that there was adequate reliability and validity in this study.

Table 3. Overall fit index of the CFA model

\begin{tabular}{lll}
\hline Fit index & Scores & Recommended threshold value \\
\hline Absolute fit measures & & \\
CMIN/df & 1.830 & $\leq 2^{\mathrm{a}} ; \leq 5^{\mathrm{b}}$ \\
GFI & 0.844 & $\geq 0.90^{\mathrm{a}} ; \geq 0.80^{\mathrm{b}}$ \\
RMSEA & 0.053 & $\leq 0.8^{\mathrm{a}} ; \leq 0.10^{\mathrm{b}}$ \\
Incremental fit measures & & \\
NFI & 0.903 & $\geq 0.90^{\mathrm{a}} ;$ \\
AGFI & 0.816 & $\geq 0.90^{\mathrm{a}} ; \geq 0.80^{\mathrm{b}}$ \\
CFI & 0.953 & $\geq 0.90^{\mathrm{a}} ;$ \\
Parsimonious fit measures & & \\
PGFI & 0.712 & The higher the better \\
PNFI & 0.808 & The higher the better \\
\hline
\end{tabular}

Note: a Acceptability: acceptable; b Acceptability: marginal 


\subsection{Structural Model}

This section presents the main result of the hypothesis testing of the structural relationship among the latent variables (Table 4, Table 5 and Figure 2.)

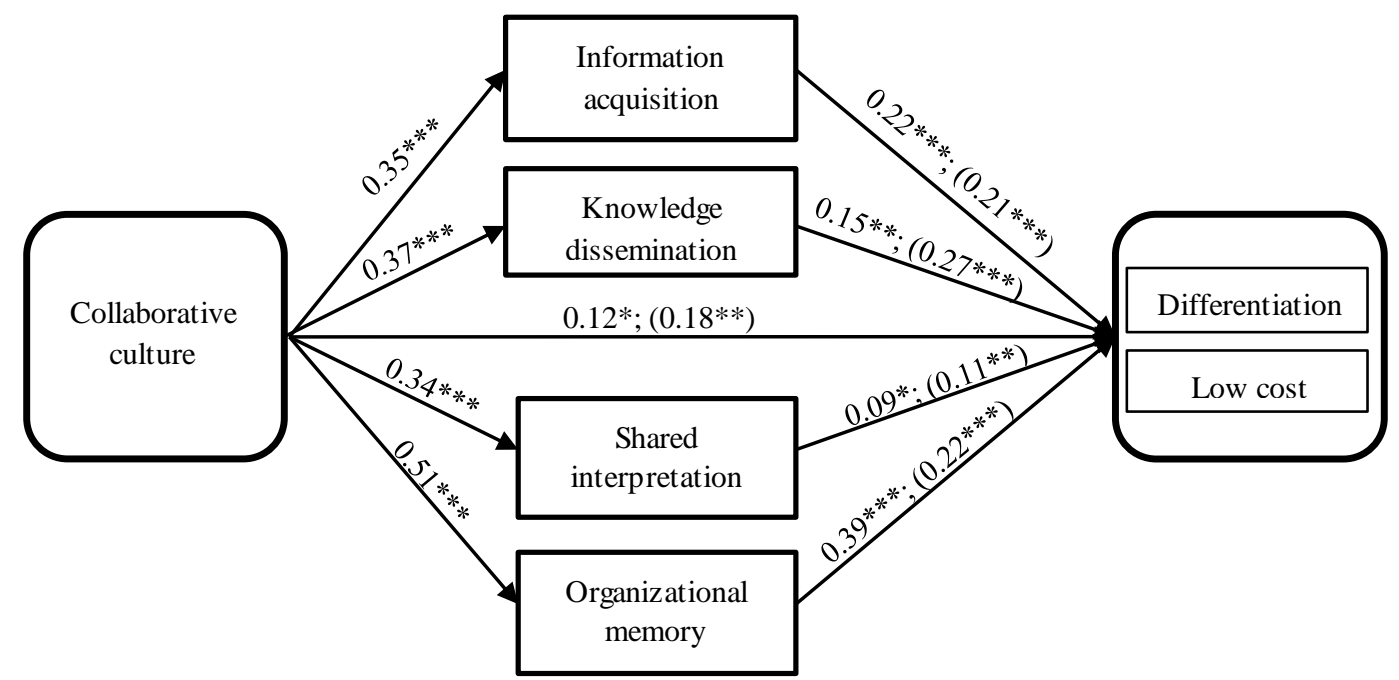

Figure 2. Path coefficients of the structural model

Note: ***significant at the 0.001 level; **significant at the 0.05 level; *significant at the 0.10 level.

(Estimate of impacts on low cost in parentheses)

Table 4. Structural model results

\begin{tabular}{lcccl}
\hline Hypotheses & $\begin{array}{c}\text { Proposal } \\
\text { effect }\end{array}$ & Estimate & $\mathrm{P}$ & Results \\
\hline H1a: CC $\rightarrow$ IA & + & $0.352^{* * *}$ & $<0.001$ & Supported \\
H1b: CC $\rightarrow$ KD & + & $0.374^{* * *}$ & $<0.001$ & Supported \\
H1c: CC $\rightarrow$ SI & + & $0.347^{* * *}$ & $<0.001$ & Supported \\
H1d: CC $\rightarrow$ OM & + & $0.512^{* * *}$ & $<0.001$ & Supported \\
H2a: CC $\rightarrow$ DA & + & $0.128^{*}$ & 0.056 & Supported \\
H2b: CC $\rightarrow$ CA & + & $0.187^{* *}$ & 0.008 & Supported \\
H3a: IA $\rightarrow$ DA & + & $0.225^{* * *}$ & $<0.001$ & Supported \\
H3b: IA $\rightarrow$ CA & + & $0.217^{* * *}$ & $<0.001$ & Supported \\
H3c: KD $\rightarrow$ DA & + & $0.152^{* *}$ & 0.007 & Supported \\
H3d: KD $\rightarrow$ CA & + & $0.272^{* *}$ & $<0.001$ & Supported \\
H3e: SI $\rightarrow$ DA & + & $0.097^{*}$ & 0.062 & Supported \\
H3f: SI $\rightarrow$ CA & + & $0.117^{* *}$ & 0.034 & Supported \\
H3g: OM $\rightarrow$ DA & + & $0.393^{* * *}$ & $<0.001$ & Supported \\
H3h: OM $\rightarrow$ CA & + & $0.222^{* *}$ & $<0.001$ & Supported \\
\hline
\end{tabular}

Note: ***significant at the 0.001 level; **significant at the 0.05 level; * significant at the 0.10 level.

\subsubsection{Direct Effect Analysis}

The results (Table 4 and Figure 2) show that, all the direct effects of each variable has on each other are quite large and statistically significant, therefore all the hypotheses are supported. Specifically: 
For H1a.b.c.d relating to the positive influence of CC on four specific parts of OL. As Table 4 and Fig.2 shown, the effects of $\mathrm{CC}$ on IA, KD, SI and $\mathrm{OM}$ have values of 0.352 ; 0.374; 0.347; and 0.512 ( $\mathrm{P}<0.001$ ), respectively. Hypotheses 1a.b.c.d were supported. It also indicates that CC's influence on OM is greater than its influence on the other parts of OL.

Hypotheses of $\mathrm{H} 2 \mathrm{a}$ and $\mathrm{H} 2 \mathrm{~b}$ relating to the positive effects of $\mathrm{CC}$ on DA and CA, the results confirm both of two hypotheses because the effects of ethical leadership on knowledge collecting and knowledge donating have statistically significant with values of $0.128(\mathrm{P}=0.056)$ and $0.187(\mathrm{P}=0.008)$, respectively. Its shows that $\mathrm{CC}$ has more important significant in the relationship with CA compared with DA (0.187>0.128).

For H3a and H3b, relating to the IA's positive effects on DA and CA. The result show that IA has larger impacts on DA (estimate value of $0.225 ; \mathrm{P}<0.001$ ) in comparis on with CA (estimate value of 0.217 ; $\mathrm{P}<0.001$ ). However, IA's effects on DA and CA are not large difference. Hypotheses H3c.d refer to the KD's positive effects on DA and CA, contrary to $\mathrm{H3a}$ and $\mathrm{H} 3 \mathrm{~b}$, The result show that $\mathrm{KD}$ has larger impacts on $\mathrm{CA}$ (estimate value of 0.275 ; $\mathrm{P}<0.001$ ) in comparis on with DA (estimate value of 0.152; $\mathrm{P}=0.007$ ).

$\mathrm{H} 3 \mathrm{e}$ and H3f refer to the positive effects of SI on DA and CA, the result show that SI has more important significant in the relationship with CA (estimate value of $0.117 ; \mathrm{p}=0.034$ ) in comparison with DA (estimate value of 0.097; $\mathrm{p}=0.062$ ). The results also confirm the positive effects of OM on DA and CA (the hypotheses of H3g and H3h, respectively). Specifically, OM has a greater impacts on DA (estimate value of $0.393 ; p<0.001$ ) in comparison with CA (estimate value of $0.222 ; \mathrm{p}<0.001$ );

\subsubsection{Indirect and Total Effect Analysis}

Our study does not just give evidence about the influence of CC on DA and CA but also discovers how this mechanis m activating through four parts of OL; direct and indirect effects as well as total effects are computed and listed in Table 5. As to the indirect effects, Table 5 firstly confirms the mediating role of OL in the relationships between $\mathrm{CC}$ and two kinds of competitive advantage.

Table 5. Direct, indirect and total effects analysis

\begin{tabular}{lcccccc}
\hline Predictor/dependent & IA & KD & SI & OM & DA & CA \\
\hline Direct effects & & & & & & \\
CC & 0.352 & 0.374 & 0.347 & 0.512 & 0.128 & 0.187 \\
IA & & & & & 0.225 & 0.217 \\
KD & & & & & 0.152 & 0.272 \\
SI & & & & & 0.097 & 0.117 \\
OM & & & & & 0.393 & 0.222 \\
Indirect effects & & & & & & \\
CC & & & & & 0.371 & 0.333 \\
Total effects & & & & & & \\
CC & & & & & 0.499 & 0.520 \\
\hline
\end{tabular}

Finally, Table 5 indicated that, CC's indirect effects on DA are greater than CA $(0.371>0.333)$, while CC's total effects on CA are greater than DA $(0.520>0.499)$. The finding implicates that, the CC's direct effects on CA are more significant than DA.

\section{Discussions, Implications and Conclusions}

Many scholars proposed that collaborative culture (CC) has relationship not only with organizational learning (OL) but also with competitive advantage, and OL has relationship with competitive advantage. However, there were no research link CC, OL and competitive advantage in a model holistically. Moreover, although there were a few researches mention the relationship between OL and competitive advantage, however it seems having no empirically research directly analyzing in fluences of four parts of OL on two kinds of competitive advantage. In this context, the 
examination of hypotheses, that were developed in our study have important contributions not only to theory but also to practice by following reasons.

First, our study contributes to fill the theoretical gaps by proposing a model discussing the influences of CC on four parts of OL, which in turn lead to differentiation competitive advantage (DA) and low cost competitive advantage (CA) in a model. The empirical findings verified the relationships between variables of the theoretical model and all the hypotheses are statistically supported. Through direct and indirect analysis, the study provides a possible mechanis $\mathrm{m}$ by which $\mathrm{CC}$ practices contribute to DA and CA. The mediating roles of specific aspects of OL in relationship between $\mathrm{CC}$ and competitive advantage are also confirmed. The implication is that $\mathrm{CC}$ practices will yield significant effects to competitive advantage directly or indirectly through information acquisition (IA), knowledge dissemination (KD), shared interpretation (SI), and organizational memory (OM). The results are contrary to the research of López et al. (2004) for concluding that CC will not create in itself as a source of competitive advantage in Spanish context. So, there needs more empirical research in future to assess and confirms the relation among these factors.

Second, an important contribution of this study is that analysis more deeply the relationship among factors by assessing: OL at four parts; competitive advantage at two kinds. As a result, finding of these relationships provides specific and useful guides for firms to have right impacts on specific factors to get right direction of selected strategy (differentiation or low cost). Specifically, Firms will implement more successful differentiation strategy by focusing efforts in the OM activities. This main reason may be that OM activities can help firms make good use of the opportunities and minimize the challenges, thereby improving brand image and status of ent erprise. In contrast, firm will implement more successful slow costs strategy by focusing efforts in the KD activities. Th is main reason may be that, these activities can help firms minimize production costs by sharing and using effectively knowledge and information about the market, competitor and itself to improve and optimize business activities.

Third, by analy zing total effects we found that CC's influences on two kinds of competitive advantage are very great. It implies that $\mathrm{CC}$ have very important role in promoting competitive advantage for firms. So, paying more attention to build a strong and positive CC (that concentrates in basic value of culture like: A long-term vision and advance management of the change, team-work, communication, risk assumption, respect and empowerment, and promoting the knowledge of individuals) is very important.

This study has some limitations. First, this study just researched the definition, dimensions and consequences of CC in general. Further researches should explore mo re deeply by accessing the research model at three levels of collaboration: a business unit, an immediate superior and coworkers in a workgroup (Sveiby \& Simons 2002). Second, this study use cross-sectional data therefore it may appear ability that causal relationships may change or even lose meaning in the long term, a longitudinal study will help to overcome this limitation and consolidate the result. Third, this study has not evaluated the relationship between latent variables when having the impact of moderator variables. So, future researches may explore more deeply the relationship between latent variables in the research model by adding moderator variables such as: firm size, firm age, industry category.

Nevertheless, the findings of this study provide a theoretical basis, which can be used to analyze relationships among $\mathrm{CC}$, specific aspects of OL, and competitive advantage, simultaneously provide empirical evidence to prove the hypotheses that $\mathrm{CC}$ and specific aspects of justice have important roles in promoting DA and CA. In which OM has more significant effects on DA while $\mathrm{KD}$ has more significant effects on CA. The findings are encouraged to bring more deeply understanding into how firms should increase competitive advantage with well awareness of collaborative culture as well as organizational learning.

\section{References}

Agarwal, R., \& Selen, W. (2009). Dynamic capability building in service value networks for achieving service innovation. Decision sciences, 40(3), 431-475. https://doi.org/10.1111/j.1540-5915.2009.00236.x

Ajmal, M. M., \& Koskinen, K. U. (2008). Knowledge transfer in project-based organizations: an organizational culture perspective. Project Management Journal, 39(1), 7-15. https://doi.org/10.1002/pmj.20031

Alavi, M., Kayworth, T. R., \& Leidner, D. E. (2005). An empirical examination of the influence of organizational culture on knowledge management practices. Journal of management information systems, 22 (3), $191-224$. https://doi.org/10.2753/MIS0742-1222220307

Armstrong, A., \& Foley, P. (2003). Foundations for a learning organization: organization learning mechanisms. The Learning Organization, 10(2), 74-82. https://doi.org/10.1108/09696470910462085 
Armstrong, J. S., \& Overton, T. S. (1977). Estimating nonresponse bias in mail surveys. Journal of marketing research, 396-402. https://doi.org/10.2307/3150783

Azadegan, A., \& Dooley, K. J. (2010). Supplier innovativeness, organizational learning styles and manufacturer performance: An empirical assessment. Journal of Operations Management, 28(6), 488-505. https://doi.org/10.1016/j.jom. 2010.02.001

Barney, J. (1991). Firm resources and sustained competitive advantage. Journal of management, 17(1), 99-120. https://doi.org/10.1177/014920639101700108

Bell, S. J., Mengüç, B., \& Widing II, R. E. (2010). Salesperson learning, organizational learning, and retail store performance. Journal of the Academy of Marketing Science, 38(2), 187-201. https://doi.org/10.1007/s 11747-009-0149-X

Brockman, B. K., \& Morgan, R. M. (2003). The role of existing knowledge in new product innovativeness and performance. Decision Sciences, 34(2), 385-419. https://doi.org/10.1111/1540-5915.02326

Bstieler, L., \& Hemmert, M. (2010). Increasing Learning and Time Efficiency in Interorganizational New Product Development Teams*. Journal of Product Innovation Management, 27(4), 485-499. https://doi.org/10.1111/j.1540-5885.2010.00731.x

Calton, J. M., \& Lad, L. J. (1995). Social contracting as a trust-build ing process of network governance. Business Ethics Quarterly, 5(02), 271-295. https://doi.org/10.2307/3857357

Carter, M. (1999). Energizing our workforce. Child Care Information Exchange, 76-81.

Chauhan, N., \& Bontis, N. (2004). Organisational learning via groupware: a path to discovery or disas ter? International Journal of Technology Management, $\quad$ 27(6-7), https://doi.org/10.1504/IJTM.2004.004904

Chenhall, R. H. (2005). Integrative strategic performance measurement systems, strategic alignment of manufacturing, learning and strategic outcomes: an exploratory study. Accounting, Organizations and Society, 30(5), 395-422. https://doi.org/10.1016/j.aos.2004.08.001

Coyne, K. P. (1986). Sustainable competitive advantage-What it is, what it isn't. Business horizons, 29(1), 54-61. https://doi.org/10.1016/0007-6813(86)90087-X

David, W., \& Fahey, L. (2000). Diagnosing cultural barriers to knowledge management. The Academy of management executive, 14(4), 113-127.

Davis, D., \& Daley, B. J. (2008). The learning organization and its dimensions as key factors in firms' performance. Human Resource Development International, 11 (1), 51-66. https://doi.org/10.1080/13678860701782352

Day, G. (1990). Mental driven strategy: Processes for creating value. New York, NY: Free Press.

DeCarolis, D. M., \& Deeds, D. L. (1999). The impact of stocks and flows of organizational knowledge on firm performance: An empirical investigation of the biotechnology industry. Strategic management journal, 20(10), 953-968. https://doi.org/10.1002/(SICI) 1097-0266(199910)20:10<953::AID-SMJ59>3.0.CO;2-3

Denison, D. R. (1990). Corporate culture and organizational effectiveness. John Wiley \& Sons.

Farrukh, M., \& Waheed, A. (2015). Learning organization and competitive advantage-An integrated approach. Journal of Asian Business Strategy, 5(4), 73.

Fornell, C., \& Larcker, D. F. (1981). Evaluating structural equation models with unobservable variables and measurement error. Journal of marketing research, 39-50. https://doi.org/10.2307/3151312

Garvin, D. (1993). Building a learning organization. Harvard Business Review, 71(4), 78-91.

Gordon, G. G., \& DiTomaso, N. (1992). Pred icting corporate performance from organizational culture*. Journal of management studies, 29(6), 783-798. https://doi.org/10.1111/j.1467-6486.1992.tb00689.x

Gould, J. M. (2009). Understanding organizations as learning systems. Strategic Learning in a Knowledge Economy, 119-140.

Hair, J. F., Black, W. C., Babin, B. J., Anderson, R. E., \& Tatham, R. L. (2006). Multivariate data analysis (6th ed.). New Jersey: Pearson Education.

Hamel, G., \& Prahalad, C. (1989). Strategic intent. Harvard Business Review, 67(3), 63-74. 
Helfat, C. E., \& Peteraf, M. A. (2003). The dynamic resource-based view: Capability lifecycles. Strategic management journal, 24(10), 997-1010. https://doi.org/10.1002/smj.332

Jiménez-Jiménez, D., \& Sanz-Valle, R. (2011). Innovation, organizational learning, and performance. Journal of business research, 64(4), 408-417. https://doi.org/10.1016/j.jbusres.2010.09.010

Jones, J. R. (2000). Developing a Teacher-Librarian Partnership in a Literature-Based Approach.

Kline, R. (2010). Principles and Practice of Structural Equation Modeling (3rd ed.). Guilford Press, New York. USA.

Kotter, J. P., \& Heskett, J. L. (1992). Organizational culture and performance. Free Press, New York, NY.

Lewis, D. (2002). Five years on-the organizational culture saga revisited. Leadership \& Organization Development Journal, 23(5), 280-287. https://doi.org/10.1108/01437730210435992

López, S. P., Peón, J. M. M., \& Ordás, C. J. V. (2004). Managing knowledge: the link between culture and organizational learning. Journal of knowledge management, 8(6), 93-104. https://doi.org/10.1108/13673270410567657

Miron, E., Erez, M., \& Naveh, E. (2004). Do personal characteristics and cultural values that promote innovation, quality, and efficiency compete or co mple ment each other? Journal of organizational behavior, 25(2), 175-199. https://doi.org/10.1002/job.237

Molina-A zorín, J. F., Tarí, J. J., Pereira-Moliner, J., López-Gamero, M. D., \& Pertusa-Ortega, E. M. (2015). The effects of quality and environmental management on competitive advantage: A mixed methods study in the hotel industry. Tourism Management, 50, 41-54. https://doi.org/10.1016/j.tourman.2015.01.008

Muronaga, K., \& Harada, V. (1999). The art of collaboration. Teacher Librarian, 27(1), 9-14.

Nunnally, J. C., \& Bernstein, I. (1994). Elements of statistical description and estimation. Psychometric Theory, 3 Edition, Edited by: Nunnally JC, Bernstein IH.

Porter, M. E. (1980). Competitive strategy: techniques for analyzing industries and competitors. New York: Free Press.

Porter, M. E. (1985). Competitive Advantage. New York: Free Press.

Ruth V, S. (2001). Developing a collaborative culture. SchoolLibrary Media Research, 2.

Sanders, N. R. (2007). An empirical study of the impact of e-business technologies on organizational collaboration and performance. Journal of Operations Management, 25(6), 1332-1347. https://doi.org/10.1016/j.jom.2007.01.008

Santos-Vijande, M. L., López-Sánchez, J. Á., \& Trespalacios, J. A. (2012). How organizational learning affects a firm's flexibility, competitive strategy, and performance. Journal of Business Research, 65(8), 1079-1089. https://doi.org/10.1016/j.jbusres.2011.09.002

Selnes, F., \& Sallis, J. (2003). Promoting relationship learning. Journal of Marketing, 67(3), 80-95. https://doi.org/10.1509/jmkg.67.3.80.18656

Slater, S., \& Narver, J. (1995). Market orientation and the learning organisation. Journal of Marketing, 59(3), 63-74. https://doi.org/10.2307/1252120

Sveiby, K.-E., \& Simons, R. (2002). Collaborative climate and effectiveness of knowledge work-an empirical study. Journal of Knowledge Management, 6(5), 420-433. https://doi.org/10.1108/13673270210450388

Thomas, K., \& Allen, S. (2006). The learning organisation: a meta-analysis of themes in literature. The Learning Organization, 13(2), 123-139. https://doi.org/10.1108/09696470610645467

Vorhies, D. W. (1998). An investigation of the factors leading to the development of marketing capabilities and organizational effectiveness. Journal of strategic marketing, 6(1), 3-23. https://doi.org/10.1080/096525498346676

Wang, E. T., \& Wei, H. L. (2007). Interorganizational Governance Value Creation: Coordinating for Information Visibility and Flexibility in Supply Chains*. Decision Sciences, 38(4), 647-674. https://doi.org/10.1111/j.1540-5915.2007.00173.x

Wang, Z., \& Wang, N. (2012). Knowledge sharing, innovation and firm performance. Expert Systems with Applications, 39(10), 8899-8908. https://doi.org/10.1016/j.eswa.2012.02.017 
Weerd-Nederhof, P. C., Pacitti, B. J., da Silva Gomes, J. F., \& Pearson, A. W. (2002). Tools for the improvement of organizational learning processes in innovation. Journal of Workplace Learning, 14(8), 320-331. https://doi.org/10.1108/13665620210449164

Weiss, E. M. (1999). Perceived workplace conditions and first-year teachers' morale, career choice co mmitment, and planned retention: A secondary analysis. Teaching and Teacher Education, 15(8), 861-879. https://doi.org/10.1016/S0742-051X(99)00040-2

Whitener, E. M., Brodt, S. E., Korsgaard, M. A., \& Werner, J. M. (1998). Managers as initiators of trust: An exchange relationship frame work for understanding managerial trustworthy behavior. Academy of management review, 23(3), 513-530.

Wu, L.-Y. (2010). Applicability of the resource-based and dynamic-capability vie ws under environmental volatility. Journal of Business Research, 63(1), 27-31. https://doi.org/10.1016/j.jbusres.2009.01.007

Yeung, A. C., Lai, K.-h., \& Yee, R. W. (2007). Organizational learning, innovativeness, and organizational performance: a qualitative investigation. International journal of production research, 45(11), $2459-2477$. https://doi.org/10.1080/00207540601020460

Zhao, Y., Li, Y., Lee, S. H., \& Chen, L. B. (2011). Entrepreneurial orientation, organizational learning, and performance: Evidence from China. Entrepreneurship theory and practice, 35(2), 293-317. https://doi.org/10.1111/j.1540-6520.2009.00359.x 